\title{
Multiplicando os gêneros nas práticas em saúde
}

\author{
Multiplying genders in health practices
}

Multiplicando los géneros en las prácticas de salud

\author{
Alexandre Costa Val(a) \\ Gabriela de Lima Gomes(b) \\ Fernando Machado Vilhena Dias ${ }^{(c)}$
}

\section{Introdução}

Apresentamos um breve relato sobre a experiência do evento "Multiplicando os Gêneros nas Práticas em Saúde", criado, inicialmente, a partir da parceria dos cursos de medicina das Universidades Federais de Ouro Preto (UFOP) e de São João del-Rei (UFSJ).

Os estudantes e profissionais da saúde, frequentemente, sentem-se despreparados e embaraçados ao lidarem com crenças, mitos ou tabus que envolvem as sexualidades dos seus pacientes ${ }^{1}$. Lacunas na formação desses profissionais constituem entraves para a mudança desse cenário. De forma geral, o tema tende a ser tratado pelo viés da matriz biológica dos corpos, reforçando a crença em entidades dicotômicas, naturalizadas e predefinidas.

A despeito das indicações das diretrizes nacionais para elaboração dos currículos médicos, habitualmente, a inserção desse conteúdo ocorre de forma fragmentada. Na prática, prioriza-se uma visão organicista, sem estabelecer qualquer diálogo com outros campos do saber ${ }^{2,3}$. Erros no diagnóstico, fragilização na relação com os pacientes e uma qualidade assistencial prejudicada são algumas das consequências da abordagem superficial do tema na graduação.

A criação de espaços de discussão envolvendo variadas disciplinas, incluindo as ciências humanas, as ciências sociais aplicadas e as artes, surge como uma resposta adequada para um assunto complexo em uma sociedade pluralizada e diversa ${ }^{4}$. Esse tipo de iniciativa é, no entanto, ainda pouco usual nos cursos de medicina.

Entendemos que esse relato pode contribuir para a fomentação de iniciativas como essa. Em nosso contexto, o pioneirismo da proposta permitiu um intercâmbio legítimo entre diversos atores sociais e disciplinas, aproximando questões relativas à diversidade dos gêneros ao campo da saúde. Esse evento constituiu, originariamente, um espaço aberto para que, a partir das vivências

\footnotetext{
(a,c) Escola de Medicina, Departamento de Saúde Mental, Universidade Federal de Ouro Preto. Campus Morro do Cruzeiro, s/n, Bauxita. Ouro Preto, MG, Brasil. 35400-000. alecostaval@ yahoo.com.br; fernandomvdias@ hotmail.com (b) Departamento de Museologia, Universidade Federal de Ouro Preto. Ouro Preto, MG, Brasil. gabiligo@gmail.com
} 
práticas, pudéssemos articular novas perspectivas para uma formação mais ampla, integrada e apoiada na construção crítica do conhecimento.

\section{O evento}

Tutorados por docentes, os alunos das ligas acadêmicas de saúde mental dos cursos de medicina, a partir de suas vivências e pesquisas teóricas, elegeram temas relacionados aos gêneros e às sexualidades para discussões sistemáticas ao longo do semestre. A ideia de se criar um evento para trocar as experiências e questionamentos advindos desses encontros estava lançada. Não tardou para que surgissem diálogos com as ciências sociais aplicadas. O envolvimento dos alunos do departamento de museologia da UFOP, tutorados por docente, possibilitou uma interface com o campo das artes, ampliando as propostas de formatação do evento.

A interação, protagonizada, sobretudo, pelos alunos da medicina e da museologia, inicialmente marcada pelas especificidades do campo de cada um, aos poucos, se constituiu como um intercâmbio de discursos, tarefas e funções. A organização da logística do evento e a concepção do cerimonial, a criação do site ${ }^{(d)}$ e dos materiais de divulgação, a seleção das obras e dos filmes e a participação ativa nos debates ocorreram em um ambiente onde já não predominavam as especialidades, mas o "saber-fazer" de cada um.

O evento ocorreu em Ouro Preto - Minas Gerais, cidade marcada pela estrutura barroca e por um ambiente acadêmico tradicional em que o tema até então era pouco discutido. Entre os dias 18 de maio e 21 de junho de 2015, foram programadas intervenções com o propósito de sensibilizar todos os participantes em relação à complexidade de um cenário formado por múltiplas e, por vezes, inclassificáveis identidades de gêneros e modos de vivenciar as sexualidades.

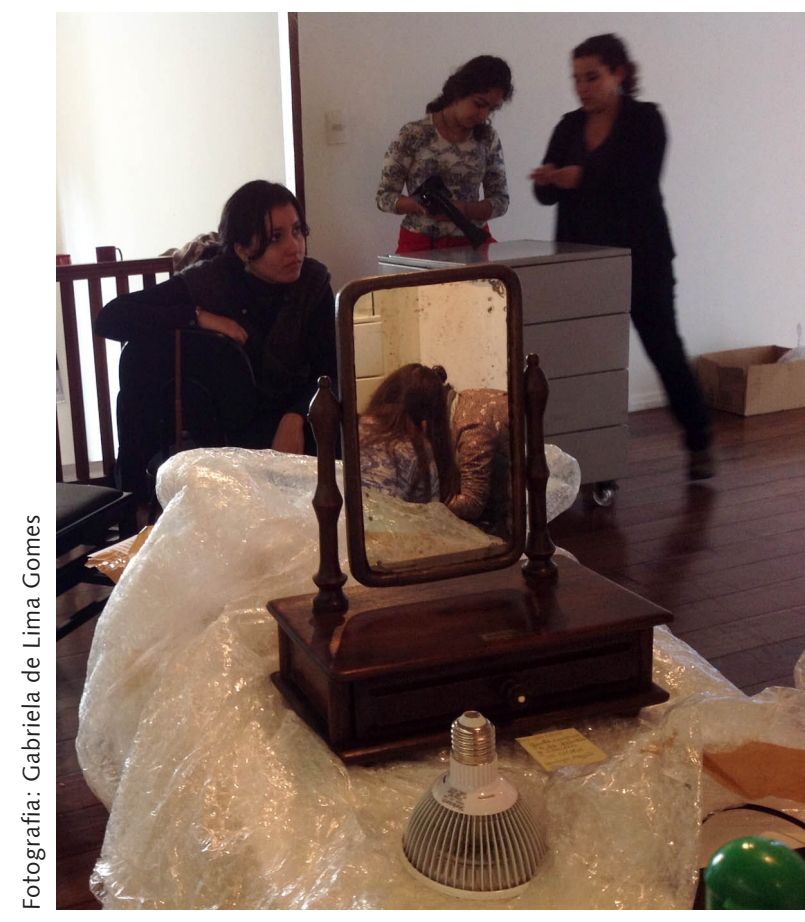

Imagem 1. Equipe da Empresa Júnior de Museologia trabalhando na montagem da Exposição Entre Elxs.
Osite do evento pode ser visto no link: https:// multiplicandogeneros. wordpress.com 
A programação teve início com a abertura da exposição Entre Elxs. Esta criou um espaço aberto e interativo de diálogo com o público, apresentando uma seleção de obras que versavam sobre as diversas possibilidades de criações dos gêneros e dos corpos no contemporâneo, a partir de apropriações singulares de diferentes realidades sociais, históricas e relacionais.

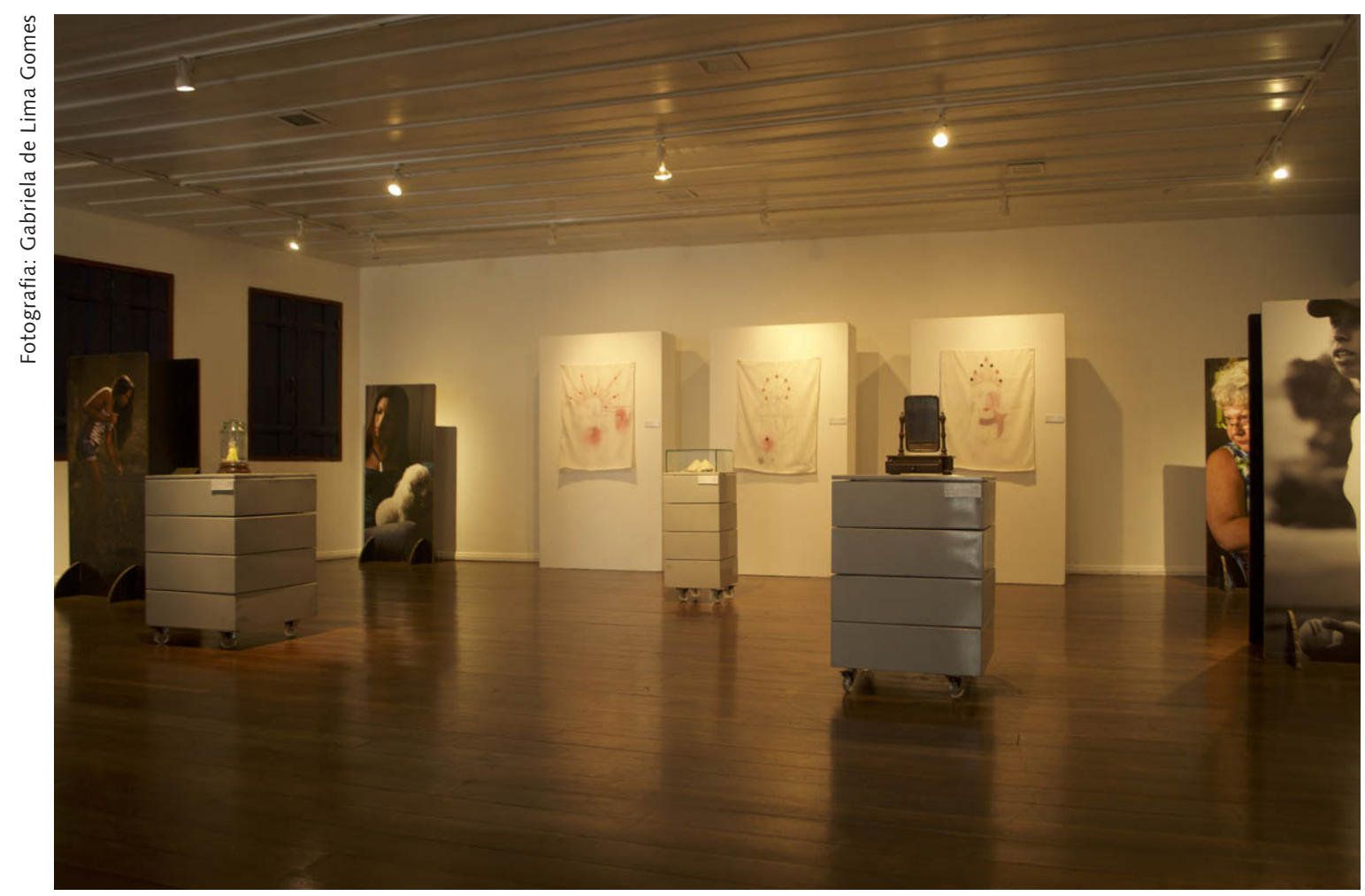

Imagem 2. Exposição Entre Elxs, Sala Ivan Marquetti, Galeria de Arte do GLTA, Ouro Preto, MG.

Essa iniciativa, coordenada pela museologia, esteve associada a atividades dialógicas de educação em saúde, voltadas para os estudantes do Ensino Médio da rede pública de educação. Estes, ao se depararem com as obras e com as ações preparadas para a mediação do tema, desenvolveram reflexões sobre a diversidade humana, que, conforme observaram vários de seus professores, serviram como ferramentas de apoio para desfazer preconceitos e trabalhar a violência direcionada às minorias. 


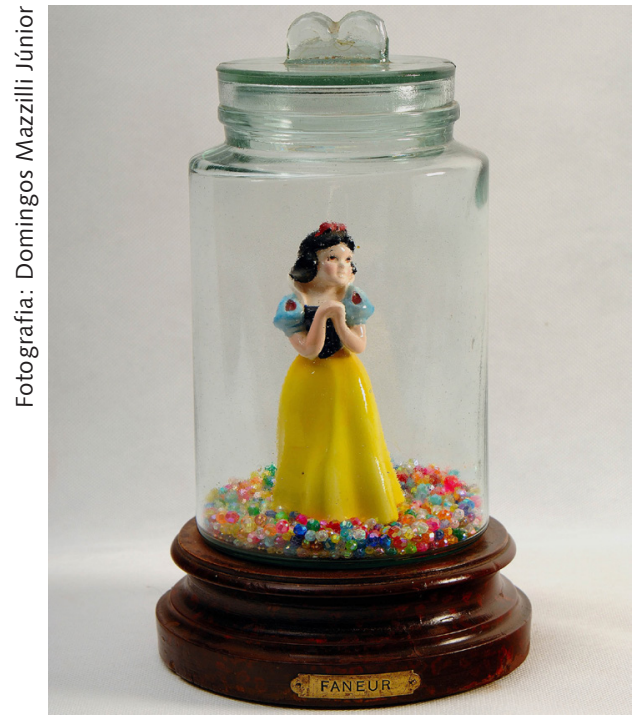

Imagem 3. Home, Sweet Home, Domingos Mazzilli, 2007. A obra vem acompanhada de uma placa com os seguintes dizeres: "Se você

for homem, retire a tampa e deixe a Branca de Neve respirar por alguns segundos".

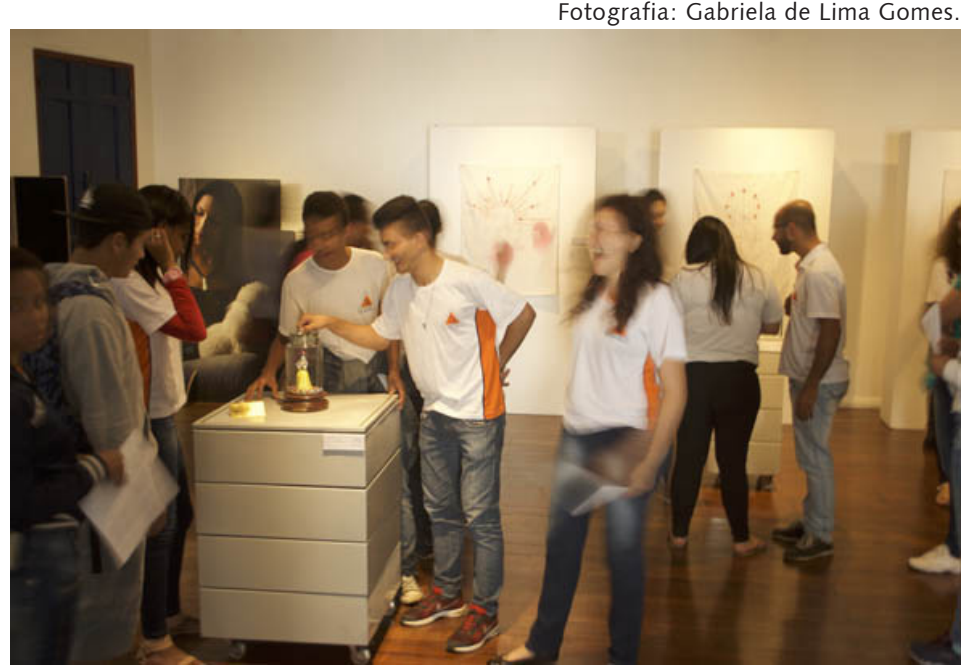

Imagem 4. Atividade educativa na Exposição Entre Elxs com alunos do $3^{\circ}$ ano do $2^{\circ}$ grau da Escola Estadual Dom Silvério - Mariana, MG

Além disso, o cinema da cidade apresentou uma mostra de filmes aberta à comunidade, seguida de debates coordenados por docentes e discentes. A participação inusitada daqueles que transitavam pelo local contribuiu sobremaneira para o enriquecimento dessa atividade. $O$ estatuto do corpo e da pele no contemporâneo, assim como as novidades biotecnológicas do século XXI e as discussões correlatas sobre bioética, foram alguns dos pontos ressaltados na conversa sobre o filme A pele que habito (Pedro Almodovar, 2011). Em uma viagem por espaços pouco explorados na floresta Amazônica, uma das diretoras do documentário Korubo: uma etnia sem fronteiras (Mariana Fagundes, Luís Abramo e Ernesto Solis, 2013) nos apresentou a história do povo indígena Korubo, recém contactado e marcado pela escassez de mulheres para garantir a reprodução e manutenção da tribo. A importância da mulher nessa cultura, o anseio pelas novas tecnologias descobertas e a criatividade diante do caos serviram como pontes para o debate a respeito de nossa sociedade atual.

Imagem 5. Imagem de divulgação do filme Korubo, 2013.

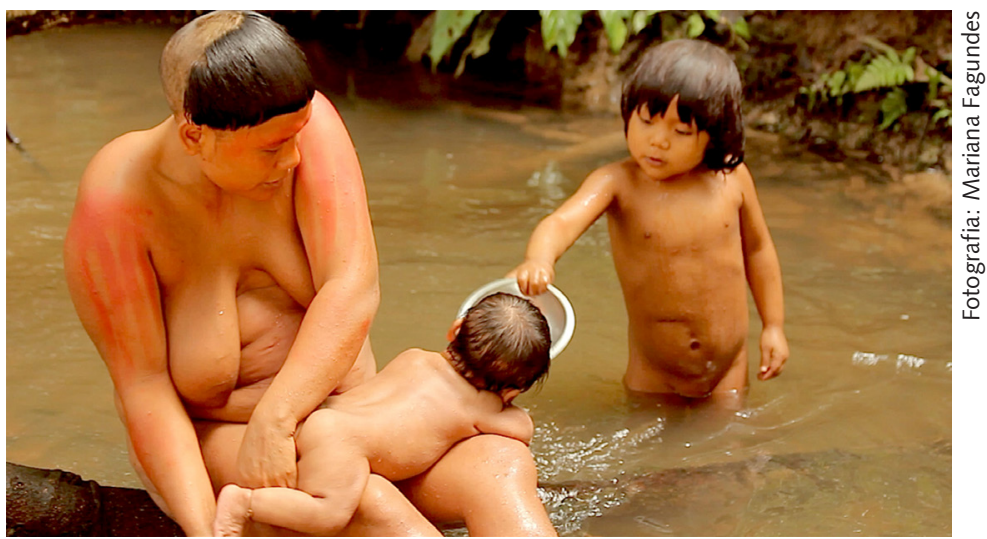


A mostra foi encerrada com o filme Meninos não choram (Kimberly Peirce, 2000), trazendo, para a cena, a discussão, conduzida pelos alunos de medicina, sobre os homens transexuais, que ainda encontram pouca visibilidade no imaginário popular.

Valendo-se de diversificados recursos audiovisuais e literários, a oficina Questões sobre gênero e imagem etnográfica conduziu os participantes por um caminho em que se abordou a história do erotismo, das sexualidades e dos gêneros. Ícones da fotografia, como Nan Goldin, estiveram presentes nessa trajetória. O convívio íntimo, mas não invasivo, dessa fotógrafa com casais que protagonizaram o ensaio The ballad of sexual dependency (1985) estimulou uma interessante conversa a respeito da arte, dos corpos contemporâneos e do cotidiano das pesquisas qualitativas em saúde.

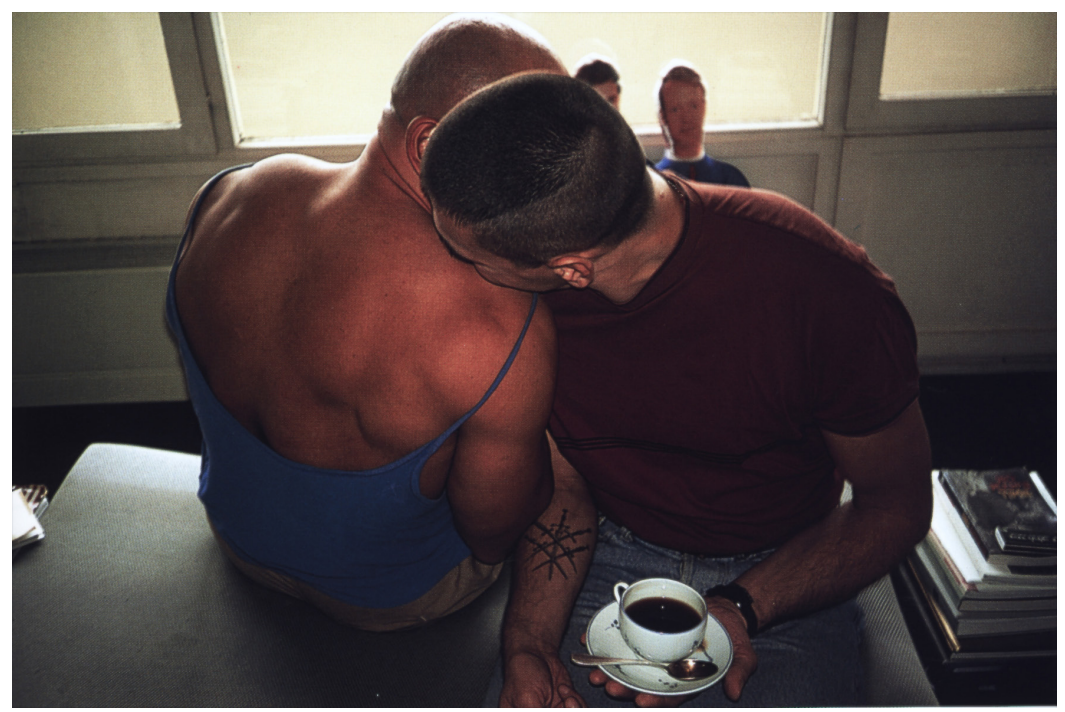

Imagem 6. Gilles and Gotscho Embracing. Nan Goldin,1992. Disponível em: https://www.flickr.com/photos/bohemea/5997174971

O simpósio se constituiu como o ponto-chave para as articulações do evento. Foi composto por quatro mesas de debates, envolvendo mais de 200 profissionais e estudantes de diversos campos do saber. Na mesa de abertura, localizou-se o referencial teórico que sustentaria as demais discussões. Partindo das perspectivas da psiquiatria, da psicanálise, da psicologia e da antropologia, os palestrantes trabalharam alguns termos como: sexo, sexualidade, gênero, desejo, orientação sexual, performatividade e incorporação (embodiment). Situações que estão cada vez mais presentes em nossa sociedade, como, por exemplo: os exames propedêuticos para se descobrir o sexo genético ou anatômico do feto, a doação de óvulos e os preconceitos em relação às variadas formas de se vivenciar as sexualidades, pavimentaram o debate. O arsenal teóricoconceitual que envolve as tentativas de criação de uma "ciência da sexualidade" parece culminar, em última instância, no fenômeno de medicalização dos corpos e da vida. No entanto, sempre há algo que escapa às investidas de teorização, normatização ou classificação, gerando impasses e controvérsias.

Na mesa A apropriação dos gêneros pelo discurso biomédico, a discussão foi retomada a partir de uma análise do discurso das produções norte-americanas sobre sexo e gênero entre os anos de 1950 e 1970. A fragilidade das políticas e práticas em saúde voltadas para os homens foi abordada como um paradigma que revela a insuficiência do discurso biomédico, que prioriza as matrizes 
biológicas dos corpos para alcançar certos grupos. Outra situação - não menos emblemática - é a adolescência. Essa foi tratada a partir do caso de Herculine, também chamada Alexine Barbin ${ }^{5}$. Atravessando de uma margem a outra, de um sexo ao outro, sua ambiguidade sexual, concreta, pôde ser lida como uma condição característica da puberdade, fase em que a desarmonia entre organismo e natureza se apresenta de forma evidente. No relato de Alexine, escrito quando ela tinha 25 anos, pronomes masculinos e femininos se alternam, revelando alguém sem lugar no mundo, aprisionado em um "entre dois". Um aprisionamento sustentado pelo discurso biomédico que, ao desconsiderar o sujeito, parece contribuir para um desfecho trágico: o suicídio.

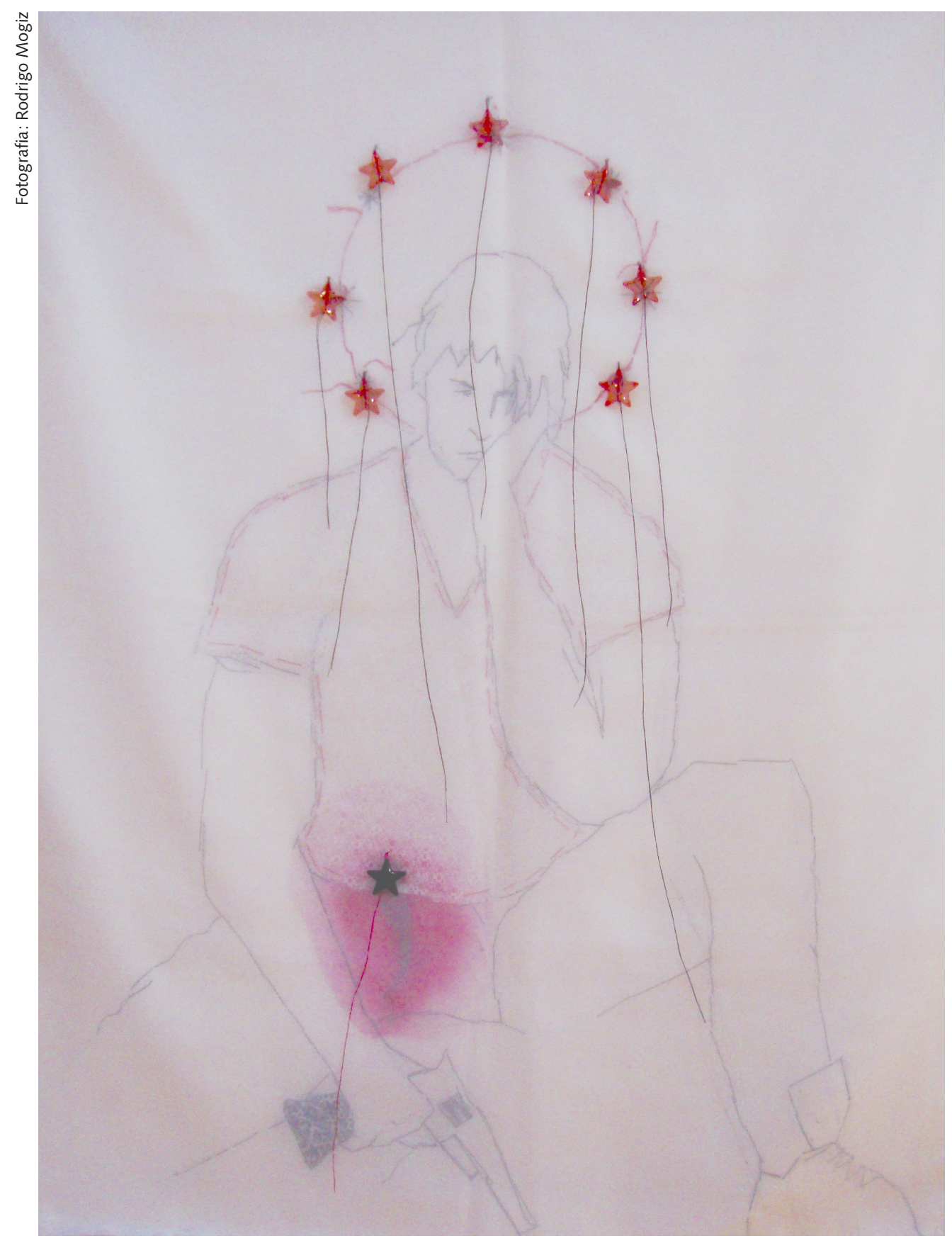

Imagem 7. Martírio Juvenil, desenho e bordados em tecido, Rodrigo Mogiz, 2003. 
A tentativa de circunscrever algo da ordem sexual também se faz presente nas novas e velhas classificações da psiquiatria. As nomeações como "transtorno de identidade de gênero" e "disforia de gênero" foram examinadas à luz das novas propostas do Manual Diagnóstico e Estatístico de Transtornos Mentais V (DSM V) na mesa Saúde mental e gêneros. O desconforto - sempre presente - na forma em que cada um de nós vivencia as próprias sexualidades levantou um questionamento pertinente: "Temos todos, em alguma medida, algo dessa disforia?" A ênfase dada à diversidade de gênero dentro de discursos da degeneração moral e da patologia foi deslocada para a potencialidade do discurso das diversidades em promover a saúde (mental). Uma sociedade em que as singularidades e diferenças podem ser acolhidas pressupõe a suspensão de hierarquias, segregações ou discriminações. Isso cria um contexto para que cada sujeito possa agenciar o seu desejo, conectando-se ao coletivo de uma forma mais saudável.

Em meio a esses debates, os participantes foram surpreendidos com dois performers vestidos com malhas que apagavam as caraterísticas sexuais e que, explorando as possibilidades e tentativas de expressão performática do prefixo "t.r.a.n.s", conduziram a plateia pelas charmosas ruas da cidade histórica em direção à exposição Entre Elxs para um pequeno intervalo. A intervenção T.R.A.N.S: um prefixo para todos e para ninguém? cativou a todos com seus movimentos poéticos, performáticos e musicais, "trans-formando" a paisagem do simpósio.

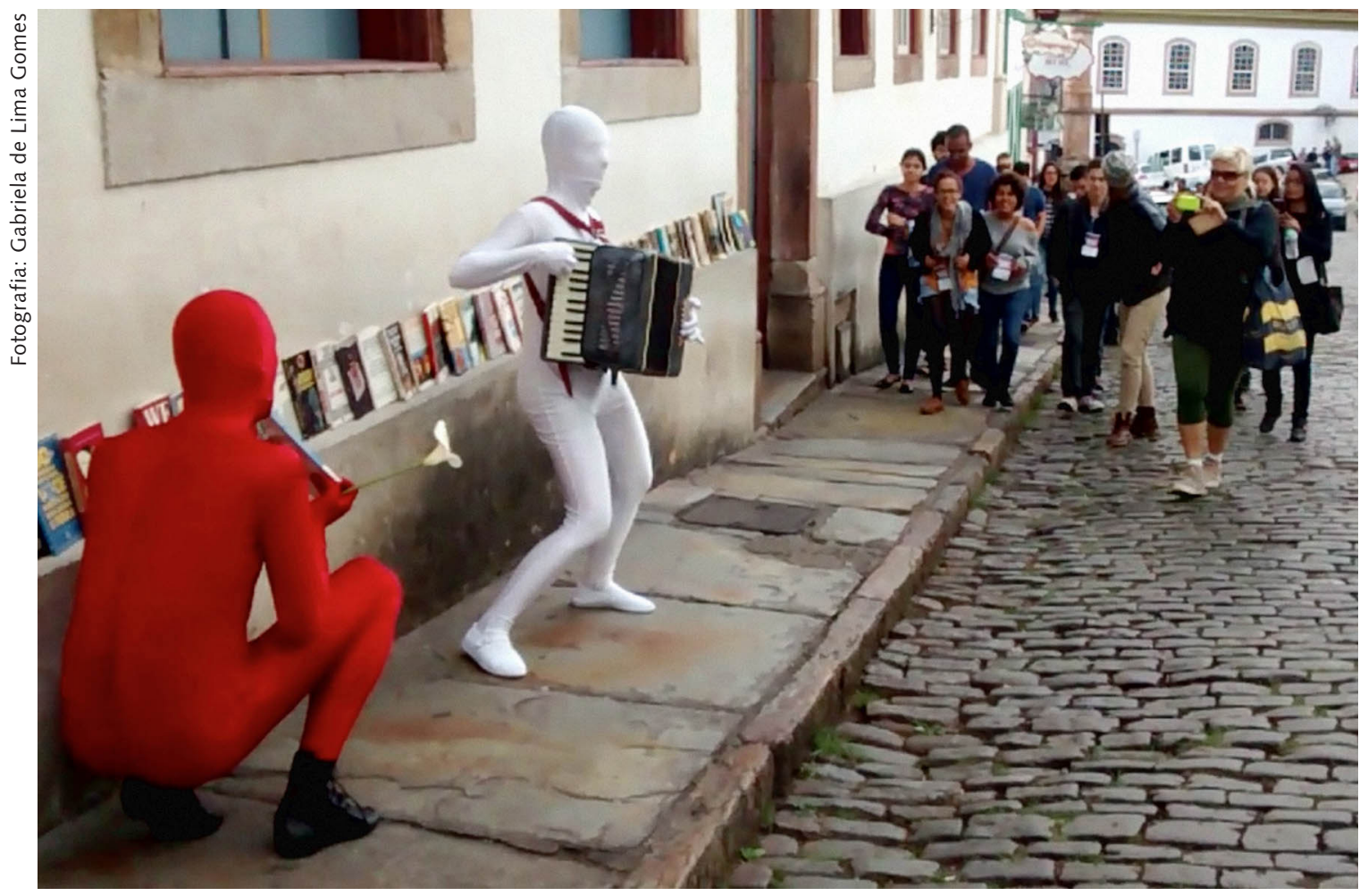

Imagem 8. T.R.A.N.S: um prefixo para todos e para ninguém? Performance executada no centro de Ouro Preto pelos artistas Leandro Acácio, Luciana Tanure e Renata Queiroz, envolvendo os participantes do simpósio. 
A mesa Transgeneralidades encerrou o simpósio. Tomando as transexualidades como paradigmas, o processo de patologização dessa condição foi discutido a partir da realidade dos movimentos desses sujeitos no Sistema Único de Saúde. A compulsoriedade da psicoterapia e a exigência de um laudo médico-psiquiátrico que chancele as intervenções foram questionadas. Desconsiderando a singularidade e as saídas que cada um encontra diante desse impasse, a lógica médico-psiquiátrica impõe a necessidade de que os sujeitos se posicionem, novamente, dentro das categorias dicotômicas preestabelecidas. Alternativas da despatologização foram apontadas de forma criteriosa para se evitar para se evitar a falta de assistência. Uma delas, por exemplo, foi a inscrição dessas pessoas nas categorias que se referem às condições de vida que influenciam o estado de saúde e o contato com os serviços (representado pela letra Z na Classificação Internacional da doenças - CID). A discussão não deixou de abarcar o paradoxo do tamanho controle no campo das intervenções voltadas para os transexuais em uma sociedade em que o excesso de interferências corporais - como as cirurgias plásticas estéticas - é regulado de forma bastante frouxa. Por fim, a necessidade de se respeitar o tempo, as invenções e criações de cada sujeito foi destacada como elemento essencial para qualquer prática em saúde.

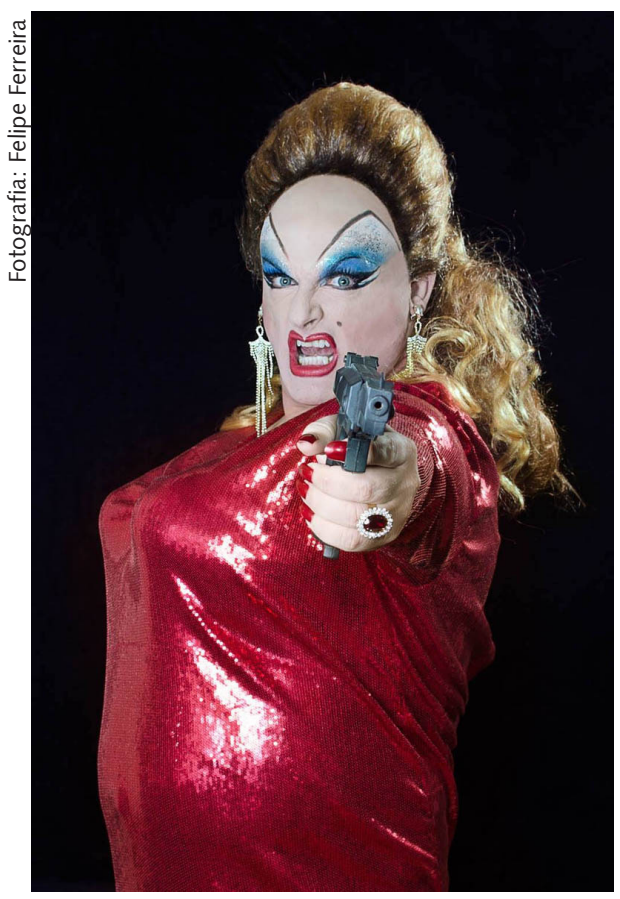

Imagem 9. Divine. Domingos Mazzilli, 2014 Compôs a ambientação do Cine Vila Rica, local em que aconteceu o Simpósio Multiplicando Géneros nas Práticas em Saúde.

\section{Considerações finais}

A interdisciplinaridade presente no simpósio "Multiplicando os Gêneros nas Práticas em Saúde" sustentou uma discussão aprofundada e reflexiva sobre uma temática complexa que exige, de saída, o envolvimento de várias perspectivas. Tratou-se de uma construção coletiva que envolveu alunos do Ensino Médio, do Ensino Superior, profissionais das mais diversas áreas do saber e muitos outros atores sociais. Esse encontro, permeado tanto pelas práticas em saúde como pelos discursos disciplinares 
(e) A época do evento coincidiu com um momento em que as denúncias de homofobia nas repúblicas e no meio acadêmico da UFOP ganhavam maior visibilidade. Além disso, ocorreu a regulamentação da utilização do nome social, considerando a identidade de gênero, na universidade. e suas formas de expressão acadêmica, deu origem a diversas mediações de natureza não apenas teórica, mas, também, política, social e cultural. Entre elas, citamos: o engajamento de alguns estudantes em projetos de pesquisa e extensão relacionados ao tema; a demanda para que o assunto seja incluído nas atividades curriculares; o comprometimento de parte da comunidade acadêmica em questões relacionadas à aceitação das diversidades ${ }^{(e)}$, e a sensibilização de professores quanto às possibilidades de abordagem das sexualidades em formatos menos artificiais e distanciados da realidade. De nossa parte, os desdobramentos incluíram a organização de um livro com os textos produzidos ao longo do processo e o desejo de repetir essa experiência.

Ao final, a construção possível não poderia ser outra: diante da multiplicidade de formas de existência do ser humano, definitivamente, não cabe a normatização. Cada um encontra uma saída mais ou menos cômoda que deve ser acolhida de forma a evitar a ruptura das conexões possíveis com o coletivo.

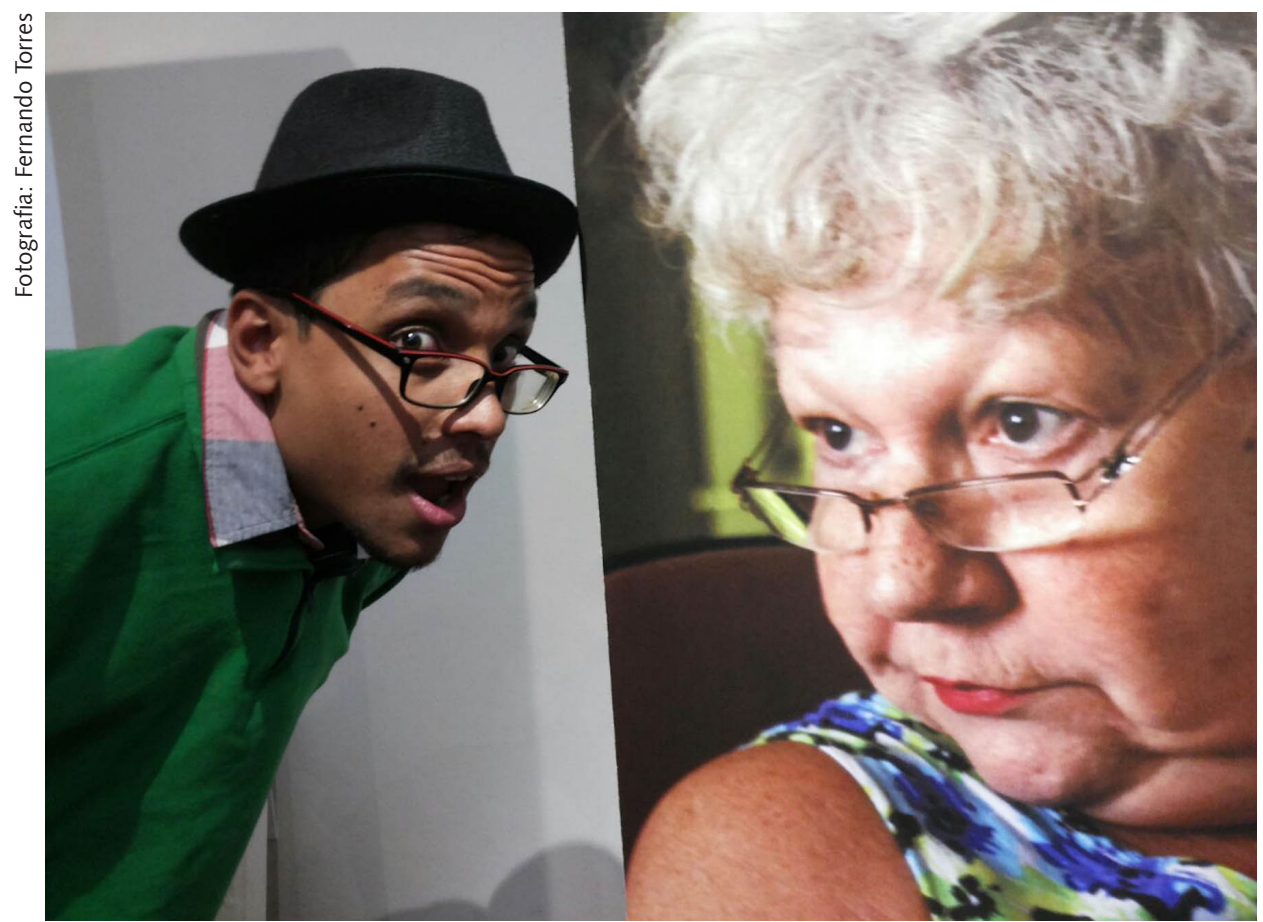

Imagem 10. Elas, Madalenas. Lucas Ávila, 2014. O artista acompanhou o cotidiano de transgêneros durante três anos na cidade de Belo Horizonte. O tamanho ampliado das fotos causou impacto naqueles que visitaram a exposição.

Essa experiência mostra a potencialidade de apropriação da polifonia discursiva sobre os gêneros e das sexualidades nas práticas em saúde - sejam elas de educação ou de assistência - para o desenvolvimento de situações favoráveis para mudanças em um contexto social mais amplo. 


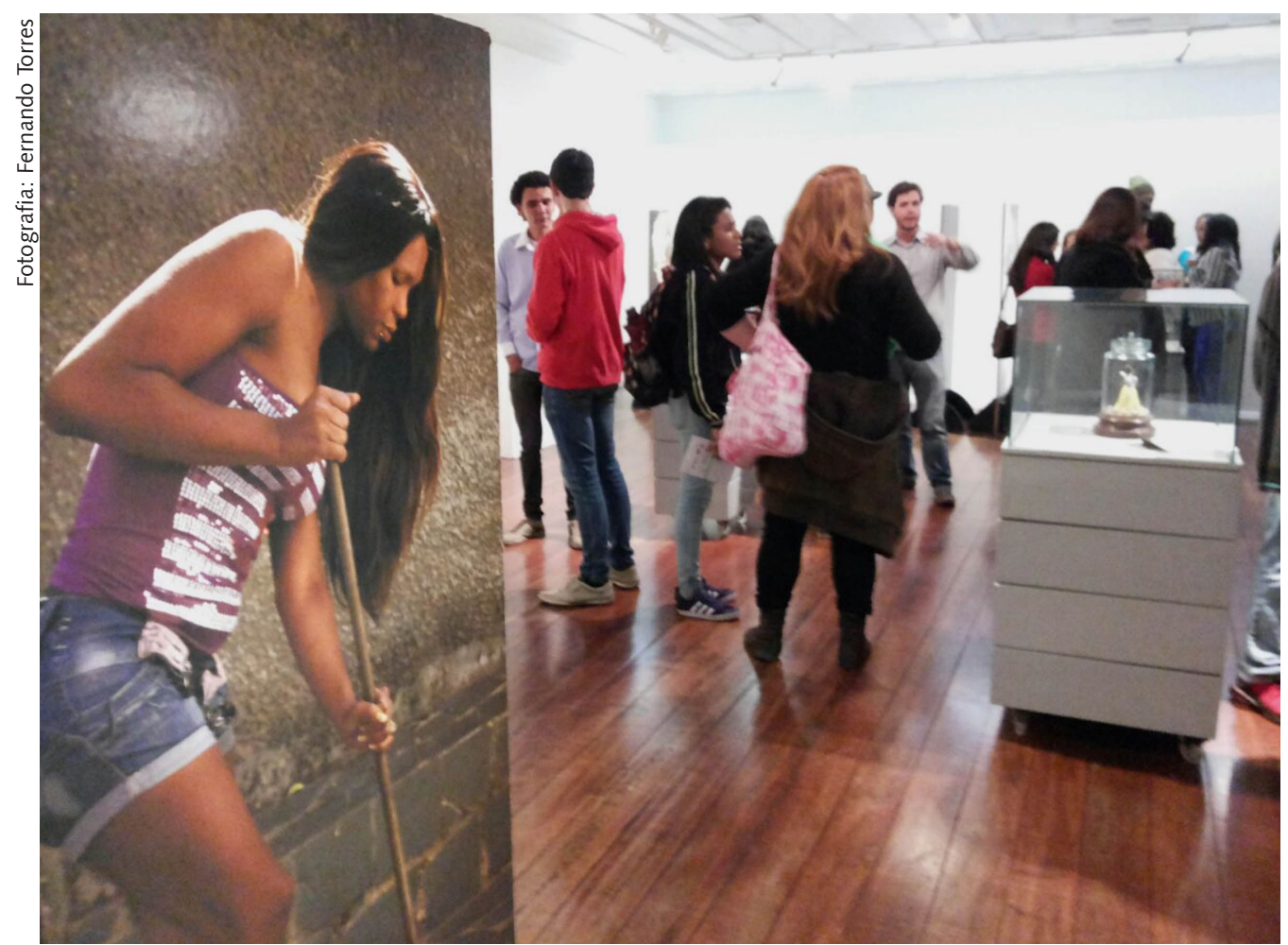

Imagem 11. Elas, Madalenas. Lucas Ávila, 2014.

\section{Colaboradores}

Os autores participaram, igualmente, de todas as etapas de elaboração do artigo.

\section{Referências}

1. Vicente $L M$, Vieira $E M$. $O$ conhecimento sobre a violência de gênero entre estudantes de Medicina e médicos residentes. Rev Bras Educ Med. 2009; 33(1):63-71.

2. Resolução no 3, de 20 de Junho de 2014. Institui Diretrizes Curriculares Nacionais do Curso de Graduação em Medicina e dá outras providências. Diário Oficial da União. 20 Jun 2014.

3. Silva MCBA. Sentidos da diversidade sexual entre estudantes de medicina [dissertação]. Uberlândia (MG): Universidade Federal de Uberlândia; 2014.

4. Rufino AC, Madeiro AP, Girao MJBC. O Ensino da sexualidade nos cursos médicos: a percepção de estudantes do Piauí. Rev Bras Educ Med. 2013; 37(2):178-85.

5. Foucault M. Herculine Barbin Ilamada Alexina B. 2a ed. Madrid: Talasa Ediciones; 2007. 